\title{
Adherence to antihyperglycemic medications and glucagon-like peptide I-receptor agonists in type 2 diabetes: clinical consequences and strategies for improvement
}

This article was published in the following Dove Press journal:

Patient Preference and Adherence

Francesco Giorgino,' Alfred Penfornis, ${ }^{2}$ Valeria Pechtner, ${ }^{3}$ Raffaella Gentilella, ${ }^{4}$ Antonella Corcos $^{4}$

'Department of Emergency and Organ Transplantation, Section of Internal Medicine, Endocrinology, Andrology, and Metabolic Diseases, University of Bari Aldo Moro, Bari, Italy; ${ }^{2}$ Service d'Endocrinologie, Diabétologie, et Maladies Métaboliques, Centre Hospitalier Sud-Francilien de Corbeil-Essonnes, Université Paris-Sud,

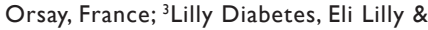
Company, Neuilly-sur-Seine, France; ${ }^{4}$ Eli Lilly Italia, Sesto Fiorentino, Italy

Video abstract

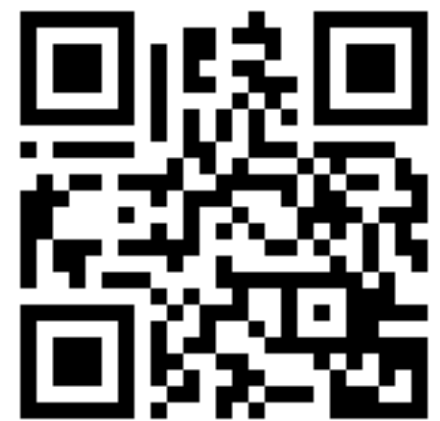

Point your SmartPhone at the code above. If you have a QR code reader the video abstract will appear. Or use:

http://youtu.be/KcFIMpFuinc

Correspondence: Francesco Giorgino Department of Emergency and Organ Transplantation, Section of Internal Medicine, Endocrinology, Andrology, and Metabolic Diseases, University of Bari Aldo Moro, Bari 70121 , Italy

Tel +390805593522

Fax +39080547815

Email francesco.giorgino@uniba.it
Abstract: Adherence to antihyperglycemic medications is often suboptimal in patients with type 2 diabetes, and this can contribute to poor glycemic control, increased hospitalization, and the development of diabetic complications. Reported adherence rates to antihyperglycemics vary widely among studies, and this may be related to differences in methodology for measuring adherence, patient populations, and other factors. Poor adherence may occur regardless of the specific regimen used and whether therapy is oral or injectable, and can be especially common in chronic, asymptomatic conditions, such as type 2 diabetes. More convenient drug-administration regimens and advances in formulations and delivery devices are among strategies shown to improve adherence to antihyperglycemic therapy, especially for injectable therapy. This is exemplified by technological developments made in the drug class of glucagon-like peptide 1-receptor agonists, which are a focus of this narrative review. Dulaglutide, albiglutide, and prolonged-release exenatide have an extended duration of action and can be administered once weekly, whereas such agents as liraglutide require once-daily administration. The convenience of once-weekly versus once-daily administration is associated with better adherence in real-world studies involving this class of agent. Moreover, provision of a user-friendly delivery device has been shown to overcome initial resistance to injectable therapy among patients with type 2 diabetes. This suggests that recent innovations in drug formulation (eg, ready-to-use formulations) and delivery systems (eg, single-dose prefilled pens and hidden, ready-attached needles) may be instrumental in encouraging patient acceptance. For physicians who aim to improve their patients' adherence to antihyperglycemic medications, it is thus important to consider the patient's therapeutic experience (treatment frequency, drug formulation, delivery device). Better adherence, powered by recent technological advances in the delivery of glucagon-like peptide 1 -receptor agonists, may thus lead to improved clinical outcomes in type 2 diabetes.

Keywords: type 2 diabetes mellitus, adherence, compliance, glucagon-like peptide 1-receptor agonists

\section{Plain-language summary}

Patients with type 2 diabetes are usually prescribed medication to reduce their blood glucose levels ("antihyperglycemic medication"), but many do not take their medication as prescribed. This is known as poor adherence, and is associated with suboptimal control of blood glucose levels. Poor adherence also increases the risk that the patient will be hospitalized due to diabetes or that they will develop complications of diabetes, such as kidney disease. The aim of this review is to highlight new developments that make it easier for patients to take their antihyperglycemic medication as prescribed. We reviewed current research papers and found that involving the 
patient in treatment decisions and improvements in drug side-effect profiles, frequency of administration, formulation, and delivery devices all help to reduce problems with adherence. Specifically, therapy that requires once-weekly rather than once-daily administration and prescription of medication that is available in a single-dose, ready-to-use pen device (eg, the glucagon-like peptide 1-receptor agonist dulaglutide) are likely to result in better patient adherence. By increasing adherence rates, medications with these features may help in controlling blood glucose levels and reducing the risk of hospitalization and complications of diabetes.

\section{Introduction}

Globally, an estimated 415 million adults aged 20-79 years have diabetes mellitus, and type 2 diabetes accounts for up to $\sim 90 \%$ of cases in high-income countries. ${ }^{1}$ Approximately $50 \%$ of patients with type 2 diabetes do not achieve adequate glycemic control, an outcome that is often related to poor adherence to medication. ${ }^{2,3}$ This suboptimal adherence is related in part to the chronic and typically asymptomatic nature of the condition. ${ }^{4}$ Poor adherence to antihyperglycemic medications can result not only in poor glycemic control but may also lead to increased hospitalization, diabetic complications, and health care resource use..$^{5-8}$ It is thus important that we continue to develop strategies to improve adherence to antihyperglycemic treatments and glycemic control, such as providing more convenient drug-administration regimens, formulations, and delivery devices. One example of a success story in this area is the evolution of insulin-replacement options, including modified and concentrated insulins that mimic the action of natural insulin and are administered using more convenient devices. ${ }^{9-11}$ Such advances are also exemplified by evolution in the drug class of glucagon-like peptide (GLP) 1-receptor agonists. This narrative review examines the extent and clinical consequences of poor adherence in type 2 diabetes and discusses strategies for improving adherence to antihyperglycemic medications, with a focus on GLP1-receptor agonists.

\section{Literature reviewed}

For the preparation of this narrative review, a comprehensive, Medical Subject Headings (MeSH) term-based search of the PubMed database was performed using the search terms "diabetes mellitus, type 2"[MeSH] AND "medication adherence"[MeSH]. The search was limited to publication dates from June 2005 to June 2016. A supplemental search was conducted focusing on GLP-1 receptor agonists (“diabetes mellitus, type 2"[MeSH] AND "medication adherence"[MeSH] AND “glucagon-like peptides"[MeSH]). All studies identified in the supplemental search were captured in the initial search. The initial search retrieved 460 papers, of which 65 were reviews. Additional relevant references were identified in the reference lists of these articles. References included in this pragmatic review of the literature were selected by the authors following a review of titles, abstracts, and/or full text.

\section{Extent and clinical consequences of poor adherence Defining and measuring adherence}

A range of definitions has been used for adherence, compliance, and persistence in the medical literature. ${ }^{4,12-15}$ While there is no clear consensus on the definitions of these terms, the World Health Organization (WHO) defines adherence to long-term therapy as "the extent to which a person's behavior - taking medication, following a diet and/or executing lifestyle changes, corresponds with agreed recommendations from a health care provider". ${ }^{4}$

The WHO also notes that the main distinction between adherence and compliance is that adherence requires the patient's agreement to the recommendations, whereas compliance does not. ${ }^{4}$ Cramer et al have suggested that adherence and compliance are synonyms and may be defined as "the extent to which a patient acts in accordance with the prescribed interval and dose of a dosing regimen". ${ }^{13}$ In other words, patients are adherent to drug therapy when they conform to the recommendations made by the health care provider with respect to timing, dosage, and frequency of taking medication. These authors stated that persistence involves treatment continuation for the prescribed duration and may be defined as "the duration of time from initiation to discontinuation of therapy". ${ }^{13}$ The definition of persistence can thus be operationalized by determining the start of treatment (or a time point during chronic therapy) to a point in time defined as the end of the observation period. However, Cramer et al also noted that clinical investigations have used different operational definitions of these terms, in some cases mixing the terms "adherence", "compliance", and "persistence" without adequate delineation. ${ }^{13}$

If changes in health outcomes are to be correctly attributed to the recommended regimen, it is important that adherence is accurately assessed. ${ }^{4}$ Although there is no "gold standard" for measuring adherence, a range of qualitative and quantitative strategies has been reported in the literature (Table 1). ${ }^{4,12,14,16-18}$ It is important to note that measures of adherence are heterogeneous, each providing different results. Therefore, results from adherence studies 
Table I Different types of qualitative and quantitative tools used to measure adherence to treatment

Qualitative (subjective) measures

- Self-report using MMAS-4 or $-8^{a}$

- Self-report using other standardized questionnaires or surveys, such as SDSCA or MARS

- Patient-reported subjective assessment of adherence (eg, in response to a simple, nonjudgmental question from the health care provider, such as "How often do you miss taking your medication?")

- Provider-reported subjective assessment of adherence (eg, based on clinical response and/or laboratory results, such as $\mathrm{HbA}_{\mathrm{Ic}}$ )

- Patient diaries or computerized logbooks

- Mobile phone real-time assessment

Notes: aProvide an adherence score by summing responses (yes $=0$, no $=1$ ) to MMAS items; higher scores indicate better adherence. ${ }^{16}$ bumber of days of medication supplied within prescription-refill period divided by number of days in refill period. ${ }^{16,19}$ cNumber of days with drug on hand divided by number of days in specified time interval. ${ }^{83}$ Data from these studies. $4,10,12,14,15,17,18$

Abbreviations: $\mathrm{HbA}_{1 \mathrm{c}}$, glycosylated hemoglobin; MARS, Medication Adherence Report Scale; MEMS, medication event-monitoring system; MMAS, Morisky Medication Adherence Scale; MPR, medication-possession ratio; PDC, proportion of days covered; SDSCA, Summary of Diabetes Self-Care Activities.

may need to be interpreted with caution, taking account of the measure used, and it can be difficult to compare results among studies.

One of the most frequently used methods to measure adherence to antihyperglycemic medications is the medication-possession ratio (MPR), which is calculated as the number of days of medication supplied within a prescription-refill period divided by the number of days in the refill period (eg, days' supply for each 3-month period divided by 90 days). ${ }^{12,16,19}$ MPR is usually determined using pharmacy-claim databases, and some studies have used derivations of MPR, ${ }^{12}$ such as the proportion of days covered (PDC; number of days during a specified time interval with drug on hand divided by the number of days in the specified time interval) (Table 1). Both MPR and PDC are usually reported as a value between 0 and 1 , or multiplied by 100 and reported as a percentage. Among the most frequently used self-report tools are the four- and eight-item versions of the Morisky Medication Adherence Scale (MMAS), which provide an adherence score by summing responses to MMAS items (yes $=0$, no $=1$; higher scores indicate better adherence $)^{16}$ (Table 1). Thresholds defining "good" or "bad" adherence can also vary, and despite limited or lack of evidence to support them, are widely used. ${ }^{4} \mathrm{~A}$ commonly used threshold for "good" adherence (or simply adherence) is when patients take at least $80 \%$ of their prescribed medication. ${ }^{4,14}$

\section{Adherence to antihyperglycemic medication}

According to the WHO, adherence to long-term therapy for chronic diseases in developed countries is only $50 \%$ on average and likely to be lower in developing countries. ${ }^{4}$ Data from a recent systematic review and meta-analysis of adherence to type 2 diabetes medication showed that adherence rates ranged widely: $38.5 \%-93.1 \%{ }^{16}$ The analysis included data from 27 studies that used validated adherence measures with a defined threshold for adherence. Of these 27 studies, nine used objective measures of adherence (MPR $>$ or $\geq 80 \%$ in seven of these nine studies) and 18 used subjective measures (four- or eight-item MMAS-based criteria in 12 of these 18 studies). Only six of the 27 studies reported adherence rates $\geq 80 \%$ among the study population.

Similar findings have been reported in other analyses, which also showed a wide range of suboptimal adherence rates to antihyperglycemic medications. ${ }^{14,17,20,21}$ These variations may be related to differences among studies in methodology for measuring adherence, adherence thresholds, and patient populations. ${ }^{14}$ In addition, a retrospective analysis conducted in the US ${ }^{22}$ showed that there were discrepancies in glycemic control between real-world studies and clinical trials in patients with type 2 diabetes, which primarily resulted from poorer adherence in the real-world setting. Importantly, reduced adherence may occur regardless of the specific regimen used and whether therapy is oral or injectable. ${ }^{14,16,17,20,21}$

\section{Reasons for poor adherence}

An important consideration when discussing reasons for poor adherence is that in contrast to acute conditions, where the benefits of treatment may be immediately apparent and patients are inherently motivated to adhere to treatment, many chronic conditions, including type 2 diabetes, are often asymptomatic, and this may be a key factor contributing to poor adherence. ${ }^{4}$

Some factors contributing to poor adherence may be largely under the patient's control, such as forgetfulness, other priorities, or a conscious decision to omit doses. ${ }^{15,23}$ 
Physicians can also adversely impact adherence by prescribing complex regimens ${ }^{15,17,23-25}$ and inadequately explaining the benefits and potential adverse events of treatment, not considering lifestyle or medication-cost issues, and having poor relationships with their patients. ${ }^{15,23}$ For example, a systematic review of 36 studies evaluating medication-taking behavior among patients with type 1 or 2 diabetes reported the following barriers to adherence: regimen complexity (more than one antihyperglycemic medication, a requirement to split tablets or draw up insulin doses), dosing frequency greater than twice daily, and adverse effects or fear of them. ${ }^{17}$ In addition, the cost of medication or the risk of certain adverse events, such as weight gain or hypoglycemia, may be more important and have a greater impact on adherence to antihyperglycemic drugs in some individuals than in others. ${ }^{26}$

It is thus important that physicians discuss these issues with their patients and develop a patient-centered treatment plan to achieve optimal adherence to therapy and clinical outcomes. ${ }^{26}$ The importance of a patient-centered approach and shared decision-making was also highlighted in a large population-based study in patients with type 2 diabetes, most of whom $(81 \%)$ were treated with oral antihyperglycemic medications without insulin. ${ }^{27}$ The study found a significant association between poor adherence and several modifiable factors related to medical care (eg, decision-making by the patient only, poor acceptability of medical recommendations, a need for medical support). ${ }^{27}$ Other factors associated with poor adherence included age $<45$ years, financial difficulties, being professionally active, and lack of family or social support. ${ }^{27}$ Health care systems can also create barriers to adherence by limiting access to health care, having high drug-purchase or contribution costs and/or copayments, and changing or restricting the drugs that can be prescribed. ${ }^{15,23}$

Multiple factors related to physicians, patients, and health care systems can also lead to clinical inertia, which has been defined as the failure of health care providers to initiate or intensify therapy when indicated. ${ }^{28,29}$ Although a full discussion of the topic is outside the scope of the current review, clinical inertia may contribute to suboptimal glycemic control for long periods of time in patients with type 2 diabetes. ${ }^{28,29}$ A patient-centered model of care, improved patient education regarding the progressive nature of the disease, and reinforcement of the need for regular treatment reviews are among strategies to address clinical inertia. ${ }^{28}$

\section{Clinical consequences of poor adherence}

An overview of studies evaluating the clinical consequences of adherence or nonadherence to antihyperglycemic medication is presented in Table 2. Most were large, retrospective, population-based studies using medical and pharmacy claimbased data for patients with type 2 diabetes, and adherence was assessed by MPR or PDC over a specified time period.

\section{Glycemic control}

Population-based studies have demonstrated that poor adherence to oral antihyperglycemic medication is associated with higher glycosylated hemoglobin $\left(\mathrm{HbA}_{1 \mathrm{c}}\right){ }^{30,31}$ A large $(\mathrm{n}=11,272)$ prospective study showed that glycemic control worsened over time (mean follow-up 5.4 years) in patients with poor adherence to oral antihyperglycemics and/or insulin. ${ }^{19}$ After adjustment for baseline $\mathrm{HbA}_{1 \mathrm{c}}$, demographic characteristics, and medical and psychiatric comorbidities, the linear mixed model showed a statistically significant reduction in $\mathrm{HbA}_{1 \mathrm{c}}$ of $0.24 \%$ (95\% CI $0.27 \%-0.21 \%, P<0.001$ ) for each $10 \%$ increase in MPR. Another population-based study showed that better adherence to insulin in patients with type 2 diabetes was associated with a reduced occurrence of hypoglycemia ${ }^{32}$ (Table 2 ).

\section{Hospitalization and mortality}

Poor adherence to oral antihyperglycemic, antihypertensive, and lipid-lowering drugs was significantly associated with increased risks for hospitalization and all-cause mortality in a population-based study that comprised 11,532 patients with unspecified diabetes. ${ }^{33}$ Patients receiving insulin were not excluded, but adherence was based on a summary PDC for filled prescriptions of oral antihyperglycemics, antihypertensives, and statins. Multivariable analyses showed significantly increased risks among poorly adherent patients for hospitalization (OR 1.58, 95\% CI 1.38-1.81) and all-cause mortality (OR 1.81, 95\% CI 1.46-2.23; P<0.001).

Several other large population-based studies have shown a relationship between good adherence to antihyperglycemic medications and reduced hospitalization rates or emergencyroom visits among patients with type 2 or unspecified diabetes ${ }^{7,34-37}$ (Table 2). For example, in the US, analysis of data from 13,428 patients with type 2 diabetes over a 1 -year follow-up showed that adherence to insulin (defined as sufficient refills for the entire quarter) and the use of a pen device (rather than vial and syringe) were each associated with reduced rates of hospitalization. ${ }^{7}$ The effect was most pronounced in adherent pen users versus nonadherent vial users, with the hospitalization rate being reduced by 0.36 per patient per year $(P<0.01)$. Glycemic control was also better among adherent pen users, and total health care costs were not statistically different between groups. ${ }^{7}$ Although these 
Table 2 Clinical consequences of adherence or nonadherence to antihyperglycemic medications

\begin{tabular}{|c|c|c|}
\hline Study & $\begin{array}{l}\text { Diabetic } \\
\text { population }^{\mathrm{a}}\end{array}$ & $\begin{array}{l}\text { Overview of study } \\
\text { design }\end{array}$ \\
\hline \multicolumn{3}{|c|}{ Glycemic control } \\
\hline $\begin{array}{l}\text { Adams } \\
\text { et } \mathrm{al}^{30}\end{array}$ & Type 2 & $\begin{array}{l}\text { Population-based study } \\
\text { using claim-based data }\end{array}$ \\
\hline $\begin{array}{l}\text { Cobden } \\
\text { et } \mathrm{a}^{32}\end{array}$ & Type $2^{\mathrm{b}}$ & $\begin{array}{l}\text { Population-based study } \\
\text { using claim-based data }\end{array}$ \\
\hline $\begin{array}{l}\text { Egede } \\
\text { et al }{ }^{19}\end{array}$ & Type 2 & $\begin{array}{l}\text { Large prospective } \\
\text { longitudinal study (mean } \\
\text { follow-up } 5.4 \text { years) }\end{array}$ \\
\hline $\begin{array}{l}\text { Pladevall } \\
\text { et al }{ }^{23,31} \\
\text { Hospital }\end{array}$ & $\begin{array}{l}\text { Type not specified } \\
\text { ation and mortality }\end{array}$ & $\begin{array}{l}\text { Population-based study } \\
\text { using claim-based data }\end{array}$ \\
\hline $\begin{array}{l}\text { Ayyagari } \\
\text { et } \mathrm{al}^{7}\end{array}$ & Type $2^{c}$ & $\begin{array}{l}\text { Population-based study } \\
\text { using claim-based data }\end{array}$ \\
\hline $\begin{array}{l}\text { Boye } \\
\text { et } \mathrm{al}^{34}\end{array}$ & $\begin{array}{l}\text { Type } 2 \text { ( } \geq 65 \text { years } \\
\text { of age) }\end{array}$ & $\begin{array}{l}\text { Population-based study } \\
\text { using claim-based data }\end{array}$ \\
\hline $\begin{array}{l}\text { Curtis } \\
\text { et } \mathrm{al}^{35}\end{array}$ & Type 2 & $\begin{array}{l}\text { Population-based study } \\
\text { using claim data }\end{array}$ \\
\hline $\begin{array}{l}\mathrm{Ho} \\
\text { et } \mathrm{al}^{33}\end{array}$ & Type not specified & $\begin{array}{l}\text { Population-based study } \\
\text { using claim data }\end{array}$ \\
\hline $\begin{array}{l}\text { Juarez } \\
\text { et } \mathrm{al}^{36}\end{array}$ & Type not specified & $\begin{array}{l}\text { Population-based study } \\
\text { using claim data }\end{array}$ \\
\hline $\begin{array}{l}\text { Nguyen } \\
\text { et al }{ }^{37} \\
\text { Renal co }\end{array}$ & $\begin{array}{l}\text { Type } 2^{d} \\
\text { plications }\end{array}$ & $\begin{array}{l}\text { Population-based study } \\
\text { using claim data }\end{array}$ \\
\hline $\begin{array}{l}\text { Chang } \\
\text { et al }{ }^{8}\end{array}$ & Type 2 & $\begin{array}{l}\text { Population-based study } \\
\text { using claim data }\end{array}$ \\
\hline
\end{tabular}

Results

More frequent refills of oral antihyperglycemics were associated with lower average $\mathrm{HbA}_{1 \mathrm{c}}$

Incidence of hypoglycemia $\downarrow$ almost two-thirds $(P<0.05)$ among patients with an MPR $\geq 80 \%$

Glycemic control worsened over time in patients with poor adherence to oral antihyperglycemics and/or insulin. Conversely, there was a significant $(P<0.00 \mathrm{I})$ reduction in $\mathrm{HbA}_{\text {lc }}$ of $0.24 \%$ for every $10 \% \uparrow$ in MPR

A $10 \% \uparrow$ in nonadherence to metformin was associated with a $0.14 \% \uparrow$ in $\mathrm{HbA}_{\mathrm{Ic}}$

Patients adherent to insulin had a significantly $(P<0.00$ I) lower predicted rate of hospitalization than those not adherent to insulin; insulin-pen use also significantly $(P<0.00 \mathrm{I}) \downarrow$ predicted hospitalization vs syringe and vial use

Adherence to all antihyperglycemic agents (assessed by PDC over 3 years)

significantly $(P<0.00 \mathrm{I})$ reduced the odds of hospitalization or ER visit, length of stay in hospital, and risk of an acute complication

Adherence to all antihyperglycemic agents (assessed by PDC over 3 years)

significantly $(P<0.00 \mathrm{I})$ reduced the odds of hospitalization or ER visit, number of hospitalizations or ER visits, and length of stay in hospital

Rates of hospitalization and all-cause mortality were significantly $(P<0.00 \mathrm{I})$ higher

for poorly adherent vs adherent patients (based on a summary PDC for filled prescriptions of oral antihyperglycemics, antihypertensives, and statins) Adherence to antihyperglycemics (oral and/or insulin), lipid-lowering agents, and antihypertensives (assessed by PDC over 4 years) was associated with $\downarrow$ odds of hospitalization or ER visits by the third year

Adherence to GLPI-receptor agonist (assessed by PDC over I year) significantly $(P<0.00 \mathrm{I})$ reduced the odds of hospitalization for any reason or related to diabetes

Nonadherence to oral antihyperglycemic medication (assessed by MPR over a mean follow-up of 5.7 years) was associated with $\uparrow$ risk of ESRD (HR I.II, $95 \% \mathrm{Cl} \mathrm{I.0I-I.23)} \mathrm{vs} \mathrm{adherence}$

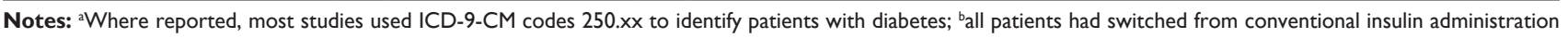
using a syringe and vial to a prefilled insulin pen; call patients were initiating insulin treatment; dall patients were initiating treatment with GLPI-receptor agonist.

Abbreviations: ER, emergency room; ESRD, end-stage renal disease; GLPI, glucagon-like peptide I; HbA ${ }_{l c}$, glycosylated hemoglobin; MPR, medication-possession ratio; PDC, proportion of days covered.

findings are of interest, in several countries vials and syringes are no longer used for insulin administration.

\section{Renal complications}

Poor adherence to oral antihyperglycemic drugs was associated with an increased risk of end-stage renal disease (ESRD) in patients with type 2 diabetes in a population-based study conducted in Taiwan ${ }^{8}$ (Table 2). The nationwide database identified 559,864 eligible patients with type 2 diabetes, including 1,695 patients with ESRD who had a mean follow-up period of 5.7 years. After adjustment for covariates, patients who were poorly adherent had a higher risk of ESRD than those who were adherent to therapy (HR 1.11, 95\% CI 1.01-1.23), and effects of poor adherence on ESRD risk remained statistically significant across a wide range of subgroups, including patients without hypertension or chronic kidney disease.

\section{Impact on health care costs}

Adherence and persistence to antihyperglycemic medications have also been associated with lower health care costs in patients with type 2 diabetes in large retrospective analyses. ${ }^{34,35,38}$ Adults $^{35}$ or patients $\geq 65$ years of age ${ }^{34}$ who were adherent to all antihyperglycemic drugs over a 3-year period (PDC $\geq 80 \%$ ) had significantly $(P<0.001)$ lower acute care ${ }^{35}$ and total health care $\operatorname{costs}^{34}$ when compared with nonadherent patients. Another analysis using data from 1,321 patients with type 2 diabetes who received liraglutide showed that patients who persisted with liraglutide (ie, those who did not have a gap in therapy $>90$ days) had significantly lower medical costs over 1 year than those who discontinued therapy.$^{38}$ However, because of higher pharmacy costs, total health care costs were higher for adherent and persistent patients than for those who did not display these characteristics. $^{38}$ 


\section{Strategies to improve adherence to antihyperglycemic medication Frequency of administration}

Although this review focuses on adherence to antihyperglycemic medication, studies in other therapeutic areas that have shown a relationship between adherence and dosage frequency ${ }^{39-41}$ may be of relevance. In a systematic review of 76 studies in which adherence to non-injectable drug therapy for various disorders, such as cardiovascular and respiratory diseases, was measured using an electronic monitoring device, an association between dose frequency and medication adherence was shown. ${ }^{39}$ Adherence rates were highest (79\%) with once-daily regimens, declining to $69 \%, 65 \%$, and $51 \%$ with two, three, or four daily doses, respectively $(P<0.001$ across dosage regimens). Once-weekly dosage administration was also associated with improved adherence compared with once-daily administration, according to the findings of a preliminary review of seven head-to-head studies of patient-administered drugs (oral, transdermal, or subcutaneous) across different conditions..$^{40}$ However, even intermittent therapy (ie, therapy administered less frequently than once daily) can be associated with suboptimal adherence rates. For example, in a study showing better adherence rates with weekly versus daily oral bisphosphonate therapy for osteoporosis, less than half the patients receiving weekly therapy had an MPR $\geq 80 \% .{ }^{41}$ This highlights the importance of patient perception of health status, in that asymptomatic patients with chronic conditions, such as osteoporosis or diabetes, generally perceive a lower risk of complications associated with poor adherence to medication than do symptomatic patients. $^{4}$

Also in the diabetes area, dosing frequency is an important consideration, given the recent introduction of once-weekly treatments for diabetes, and available data suggest that adherence to antihyperglycemic medication may be enhanced by the introduction of less frequent dosing. ${ }^{40,42}$ Results of a large patient-preference survey of 1,516 adults with type 2 diabetes showed that once-weekly injectable antihyperglycemic therapy was generally viewed positively (compared with daily medications), particularly among current injection users, because of greater convenience and improved quality of life. ${ }^{42}$

\section{Pill burden and dosage formulations}

Strategies that are likely to be successful in improving adherence to antihyperglycemic medication include improved delivery systems for injectable medications, ${ }^{43-45}$ and for patients receiving oral therapy, use of fixed-dose combination therapy (FDCT), rather than coadministered dual therapy. ${ }^{46,47}$ Perhaps surprisingly, Kirkman et $\mathrm{al}^{48}$ showed in an analysis of pharmacy-claim data for $>200,000$ patients with type 2 diabetes that adherence (MPR $\geq 0.8$ ) to noninsulin antihyperglycemic medications (oral therapy or GLP1-receptor agonists) was independently associated with higher total pill burden. In this study, total pill burden included all oral maintenance medication prescriptions filled, for diabetes and for other conditions, and was calculated by multiplying the average number of maintenance medications per month by the average number of oral maintenance pills per day. ${ }^{48}$

In contrast to the association between higher total pill burden and better adherence reported by Kirkman et $\mathrm{al}^{48}$ in their analysis of pharmacy-claim data for patients with type 2 diabetes, studies in patients with other conditions have generally found the opposite (ie, reduced adherence with higher pill burden), ${ }^{49-51}$ and physicians typically strive to reduce pill burden in patients with diabetes. ${ }^{52}$ FDCT may help in this regard. ${ }^{47,53}$ Among patients with type 2 diabetes receiving oral therapy, FDCT was associated with better adherence than other oral antihyperglycemic therapies (monotherapy or coadministered dual oral therapy) in a retrospective cohort analysis. ${ }^{46}$ Median MPRs were 1.00 for FDCT, 0.89 for coadministered dual therapy, and 0.73 for monotherapy. Using an MPR threshold $\geq 80 \%$ for adherence, $68.5 \%, 60.3 \%$, and $43.9 \%$ of patients receiving the respective therapies were deemed adherent. Similar findings were reported in a meta-analysis of ten studies comparing adherence with oral FDCT and coadministered dual oral therapy in patients with type 2 diabetes. ${ }^{47}$ Overall, results showed that FDCT was associated with better adherence (measured by MPR) and glycemic control (measured by $\mathrm{HbA}_{1 c}$ ) than coadministered dual oral therapy.

Advances in dosage-delivery systems, such as insulin-pen devices, can also improve adherence in patients receiving injectable therapy ${ }^{43-45}$ Compared with the vial-and-syringe method of administration, which is no longer used for insulin administration in several countries, insulin pens are more accurate and convenient, less painful, and increase mealtime flexibility. ${ }^{43,45}$ They can also overcome barriers to the use of insulin associated with the vial-and-syringe approach, such as difficulty in transporting equipment, anxiety about selfinjection, fear of injection, lengthy training, and social embarrassment. ${ }^{45}$ Most studies evaluating adherence to insulin-pen devices have shown higher adherence rates after switching to a pen device from the vial-and-syringe method, and some have shown better clinical outcomes, such as reduced hypoglycemia, hospital visits, and physician visits. ${ }^{45}$ 


\section{Shared decision-making}

One strategy that has potential to improve adherence to antihyperglycemic medication and is advocated by the American Diabetes Association and the European Association for the Study of Diabetes ${ }^{54,55}$ is that of shared decisionmaking: where a physician and patient make health-related decisions using a consultative process that considers not only the benefits and harms of therapy but also the patient's values, preferences, and circumstances.$^{56}$ Although to date shared decision-making has not been shown to significantly improve adherence to antihyperglycemic medications in patients with type 2 diabetes (in part because of small study size and limited statistical power), ${ }^{57}$ it has been shown to increase adherence and provide better clinical outcomes in other conditions, such as poorly controlled asthma. ${ }^{58}$

\section{Other factors}

Adherence to antihyperglycemic medication may also be enhanced by multifactorial behavioral and educational interventions, ${ }^{59}$ as well as patient- and physician-based factors. ${ }^{48}$
For example, in the previously mentioned study by Kirkman et $\mathrm{al}^{48}$ adherence to noninsulin antihyperglycemic medications was also independently associated with older age, male sex, higher education level, greater income, use of mail-order pharmacies (vs retail pharmacies), primary-care prescribers (vs non-endocrinology specialist prescribers), and lower copayments.

\section{GLPI-receptor agonists: evolution to improve adherence}

GLP1-receptor agonists improve glycemic control, promote weight loss, and have a low risk of hypoglycemia, except when used in combination with insulin or sulfonylureas. ${ }^{60}$ Because all the available agents require subcutaneous injection (Table 3), adherence to GLP1-receptor-agonist therapy may be increased by the provision of drugs with more convenient dosing schedules, formulations, and injection devices. Indeed, GLP1-receptor agonists provide a good example of how technological advances may lead to increased adherence to antihyperglycemic medications in patients with type 2 diabetes.

Table 3 Comparative features of glucagon-like peptide I-receptor agonists

\begin{tabular}{|c|c|c|c|c|c|c|}
\hline Parameter & $\begin{array}{l}\text { Albiglutide } \\
\text { (Eperzan) }\end{array}$ & $\begin{array}{l}\text { Dulaglutide } \\
\text { (Trulicity) }\end{array}$ & $\begin{array}{l}\text { Exenatide } \\
\text { (Byetta) }\end{array}$ & $\begin{array}{l}\text { Exenatide } \\
\text { (Bydureon) }\end{array}$ & $\begin{array}{l}\text { Liraglutide } \\
\text { (Victoza) }\end{array}$ & $\begin{array}{l}\text { Lixisenatide } \\
\text { (Lyxumia) }\end{array}$ \\
\hline$t_{\max }^{a}$ & $3-5$ days & 48 hours & 2 hours & NR & $8-12$ hours & $\mathrm{I}-3.5$ hours \\
\hline & 5 days & $4.5-4.7$ days & 2.4 hours & NR & 13 hours & 3 hours \\
\hline $\begin{array}{l}\text { Time to steady } \\
\text { state }^{a}\end{array}$ & $3-5$ weeks & $2-4$ weeks & NR & 6-7 weeks & NR & NR \\
\hline $\begin{array}{l}\text { Administration } \\
\text { frequency }^{b}\end{array}$ & Once weekly & Once weekly & Twice daily & Once weekly & Once daily & Once daily \\
\hline Delivery devices & $\begin{array}{l}\text { Single-dose dual } \\
\text { chamber prefilled } \\
\text { pens ( } 30 \mathrm{mg} \text {, } \\
50 \mathrm{mg})\end{array}$ & $\begin{array}{l}\text { Single-dose prefilled } \\
\text { pens }(0.75 \mathrm{mg} \text {, } \\
\text { I. } 5 \mathrm{mg})\end{array}$ & $\begin{array}{l}\text { Multidose } \\
\text { prefilled pens } \\
\text { (5 } \mathrm{gg} / \text { dose, } \\
10 \mu \mathrm{g} / \text { dose })\end{array}$ & $\begin{array}{l}\text { Single-dose dual- } \\
\text { chamber pen containing } \\
\text { powder }(2 \mathrm{mg}) \text { and } \\
\text { solvent for prolonged- } \\
\text { release suspension and } \\
\text { single-dose prefilled pen } \\
\text { for prolonged-release } \\
\text { suspension }(2 \mathrm{mg})\end{array}$ & $\begin{array}{l}\text { Multidose } \\
\text { prefilled pen } \\
\text { (device delivers } \\
0.6,1.2 \text {, or } \\
1.8 \mathrm{mg} / \text { dose) }\end{array}$ & $\begin{array}{l}\text { Multidose prefilled } \\
\text { pens (I0 } \mu \mathrm{g} / \text { dose, } \\
20 \mu \mathrm{g} / \text { dose })^{\mathrm{c}}\end{array}$ \\
\hline $\begin{array}{l}\text { Reconstitution } \\
\text { required? }\end{array}$ & Yes & No & No & $Y_{e s}^{d}$ & No & No \\
\hline $\begin{array}{l}\text { Need to attach } \\
\text { needle to pen? }\end{array}$ & Yes & No & Yes & Yes & Yes & Yes \\
\hline Need to prime pen? & No & No & Yes & No & Yes & Yes \\
\hline $\begin{array}{l}\text { Incidence of } \\
\text { injection-site } \\
\text { reactions }^{\mathrm{e}}\end{array}$ & $\begin{array}{l}\text { I5\% (vs } 7 \% \text { with all } \\
\text { comparators); led } \\
\text { to discontinuation } \\
\text { in } 2 \% \text { of patients, } \\
\text { but reactions } \\
\text { generally mild in } \\
\text { intensity }\end{array}$ & $\begin{array}{l}\text { I.9\%; potential } \\
\text { immunorelated } \\
\text { injection-site } \\
\text { reactions (rash, } \\
\text { erythema) reported } \\
\text { in } 0.7 \% \text { of patients } \\
\text { and usually mild }\end{array}$ & $\begin{array}{l}5.1 \% \text { in trials } \\
\geq 16 \text { weeks; } \\
\text { reactions } \\
\text { usually mild } \\
\text { and usually did } \\
\text { not result in } \\
\text { discontinuation }\end{array}$ & $\begin{array}{l}16 \% \text { (vs } 2 \%-7 \% \text { with } \\
\text { comparators) over } \\
\text { a 6-month period; } \\
\text { reactions generally mild } \\
\text { and usually did not lead } \\
\text { to discontinuation }\end{array}$ & $\begin{array}{l}2 \% \text { in trials } \\
\geq 26 \text { weeks } \\
\text { in duration; } \\
\text { reactions } \\
\text { usually mild }\end{array}$ & $\begin{array}{l}3.9 \% \text { (vs } 1.4 \% \text { with } \\
\text { placebo) in the main } \\
24 \text {-week period of } \\
\text { clinical trials; most } \\
\text { reactions mild and } \\
\text { did not result in } \\
\text { discontinuation }\end{array}$ \\
\hline
\end{tabular}

Notes: approximate values; ball GLPI-receptor agonists administered subcutaneously; calso available as a treatment-initiation pack containing both doses of multidose

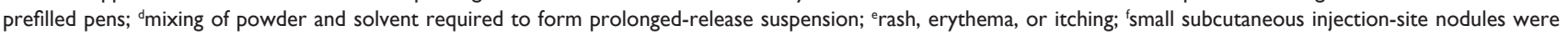
frequently observed in clinical trials (related to this specific dosage formulation of exenatide). Data from these studies. ${ }^{70-72,84-86}$

Abbreviations: GLPI, glucagon-like peptide I; NR, not reported; $t_{\max }$, time to peak plasma concentration; $t_{1 / 2}$, half-life. 


\section{Frequency of administration}

As the GLP1-receptor-agonist drug class has evolved, administration schedules have become more convenient in terms of dosing frequency. For example, when exenatide was introduced, it required twice-daily dosing. However, development of an extended-release formulation means that once-weekly administration of exenatide is now possible using the new formulation. Other recently developed GLP1-receptor agonists, such as dulaglutide and albiglutide, have an extended duration of action and can thus be administered once weekly. In contrast, agents like liraglutide and the shorter-acting drug lixisenatide still require once-daily dosing (Table 3 ).

A substantial body of data supports a relationship between reduced dosing frequency and improved adherence. In a retrospective analysis using claim data from 3,623 patients with type 2 diabetes, once-daily liraglutide was associated with significantly better adherence than twice-daily exenatide. ${ }^{61}$ The OR for poor adherence (MPR $<80 \%$ ) with exenatide versus liraglutide was 1.33 (95\% CI 1.16-1.53, $P<0.0001$ ). In another retrospective analysis that included data from 11,961 patients with type 2 diabetes, once-daily liraglutide was associated with an MPR of 0.67 and a persistence rate of $47 \%$ at 12 months, results that were generally similar to those for several orally administered once-daily agents included in the evaluation (eg, dapagliflozin $5 \mathrm{mg}$ MPR 0.67 , persistence $40 \%$; sitagliptin MPR 0.75 , persistence $48 \%$ ). ${ }^{62}$ However, canagliflozin was associated with better adherence and persistence rates than all comparators in this study.

Patients with type 2 diabetes initiating GLP1-receptoragonist therapy were significantly $(P<0.001)$ more likely to achieve an adherence rate of $\geq 80 \%$ (assessed by PDC) if treated with once-weekly exenatide than with more frequently administered GLP1-receptor agonists, according to findings of a large retrospective cohort study using claim data from $>22,000$ patients. ${ }^{63}$ Similarly, a recent Internet-based discrete-choice experiment survey of 1,482 injection-naïve patients with type 2 diabetes showed that a GLP1-receptor-agonist profile similar to that of once-weekly exenatide (single pen device) was preferred over once-daily liraglutide (OR 3.36, $P<0.001$ ) when efficacy was assumed to be equal. ${ }^{64}$ Other findings of the study revealed that the three most important attributes influencing preferences were adverse events, efficacy, and dosing frequency, whereas needle size, device size, and required preparation time were least important. ${ }^{64}$

An analysis of data from three Phase III randomized controlled trials comparing weekly albiglutide injections with daily oral antihyperglycemic medications for $1-3$ years showed that overall adherence (assessed by pen/pill count at each visit and calculated as the total number of administered doses divided by the total number of doses on the last completed visit) was high in all treatment groups, but was better with weekly albiglutide than with daily oral therapy. ${ }^{65}$ The authors noted that adherence to therapy in controlled clinical trials is generally higher than in clinical practice, and that further studies are needed to confirm these findings in a real-world setting. Interestingly, reductions in $\mathrm{HbA}_{1 \mathrm{c}}$ with GLP1-receptor agonists or dipeptidyl peptidase 4 inhibitors have been greater in randomized controlled trials than in a real-world setting (assessed by retrospective analysis of claim data), and regression analysis showed that poor adherence accounted for $75 \%$ of the difference for both drug classes. ${ }^{22}$

A real-world setting was used for a recent retrospective observational study that explored adherence in patients with type 2 diabetes who were receiving treatment with once-weekly dulaglutide, once-weekly exenatide, or oncedaily liraglutide. ${ }^{66}$ This study involved 2,415 patients per arm for the dulaglutide versus once-weekly exenatide comparison and 2,037 patients per arm for the dulaglutide versus liraglutide comparison. Propensity-score matching was used to adjust for any possible treatment-selection bias. After a 6-month follow-up period, adherence ( $P D C \geq 80 \%$ ) was $54 \%$ with dulaglutide compared with $38 \%$ with onceweekly exenatide $(P<0.0001)$; corresponding values for dulaglutide versus liraglutide were $54 \%$ versus $44 \%$, respectively $(P<0.0001)$. The proportion of patients who discontinued treatment within the 6-month follow-up was also significantly lower with dulaglutide than with onceweekly exenatide $(26 \%$ vs $48 \%, P<0.0001)$ or liraglutide $(28 \%$ vs $36 \%, P<0.0001)$ and mean persistence (number of days on treatment) was significantly higher with dulaglutide than with once-weekly exenatide (148 vs $124, P<0.0001$ ) or liraglutide (146 vs $137, P<0.0001$ ). The superior adherence, lower discontinuation rate, and higher persistence for dulaglutide versus once-weekly exenatide and liraglutide ${ }^{66}$ and the superior adherence data for once-daily liraglutide versus twice-daily exenatide ${ }^{61}$ reported here are strengthened by the real-world nature of the data.

Frequency of injection (weekly vs daily) was identified as the most important feature among hypothetical GLP1receptor-agonist profiles in a patient-preference survey of 184 injection-naïve patients with type 2 diabetes. ${ }^{67}$ The survey included a series of 10 questions regarding a pair of hypothetical GLP1-receptor agonists with equivalent efficacy and adverse events, but with different profiles otherwise. Preferences for all other GLP1-receptor-agonist attributes (eg, type of injection device) in this discrete-choice experiment 
were dependent on frequency of injection (ie, the estimated preference parameter on the interaction between injection frequency and each treatment feature was statistically significant).

Efficacy, side effects, and dosage frequency were the most influential attributes of GLP1-receptor agonists in a UK discrete-choice experiment in 297 injection-naïve patients with type 2 diabetes. ${ }^{64}$ The study showed significant patient preference for a hypothetical weekly GLP1-receptor agonist over a once-daily agent (reflecting exenatide once weekly vs liraglutide once daily), and there were also preferences for a multiuse pen versus other devices and for no dosage titration versus titration. Also of interest are the findings of another discrete-choice experiment performed in the UK, ${ }^{68}$ which involved interviewing 243 injection-naïve patients with type 2 diabetes to assess preferences for various attributes of GLP1-receptor agonists (dosing frequency, change in $\mathrm{HbA}_{1 \mathrm{c}}$, change in weight, type of delivery system, frequency of nausea, frequency of hypoglycemia). Although the drug profiles were modeled on the attributes of dulaglutide and liraglutide, no product names were mentioned to the interviewees. This study found that when differences in efficacy were small, the dosage frequency and delivery system were most important to these patients. Significantly more patients preferred the dulaglutide profile to the liraglutide profile $(83.1 \%$ vs $16.9 \%, P<0.0001)$. Weight change and hypoglycemia comprised $5.9 \%$ and $3 \%$, respectively, of calculated relative-importance values in this study, ${ }^{68}$ although corresponding relative-importance values for these events in a similar study with oral antihyperglycemic medication profiles were somewhat higher $(20.6 \%$ and $24.7 \%){ }^{69}$ These differences may reflect a relatively greater importance that patients receiving injectable therapy place on dosage frequency and delivery systems compared with patients receiving oral antihyperglycemics, with regard to changes in body weight and hypoglycemia.

\section{Formulation and injection device}

Advances in dosage formulation may also increase adherence to GLP1-receptor-agonist therapy. For example, there are important differences in reconstitution and preparation procedures prior to administration for the three GLP1-receptor agonists that are administered once weekly (Table 3). Abilglutide single-dose dual chamber prefilled pens must be twisted to mix the medication powder and solvent, then gently rocked from side to side five times, placed into a clean cup, and left for 15 minutes (30 mg dose) or 30 minutes (50 mg dose) to allow the medication powder to dissolve. ${ }^{70}$ Onceweekly exenatide prefilled pens contain medication powder and solvent, which form a prolonged-release suspension when mixed..$^{71}$ After twisting the knob of the pen to allow the components to mix, the pen must be tapped firmly against the palm of the hand and rotated every few taps until a uniformly cloudy suspension with no clumps is obtained. Dulaglutide single-dose prefilled pens come with the active drug already in solution, and are ready to use without the need for mixing. ${ }^{72}$ The availability of dulaglutide as a ready-to-use drug in solution reflects formulation and bioengineering advances designed to overcome the issue of reconstitution.

Convenience is also a feature of new formulations of liraglutide and lixisenatide, which have been developed in fixed-dose combinations with basal insulin (insulin degludec and liraglutide; insulin glargine and lixisenatide). ${ }^{73} \mathrm{CT}$ with a GLP1-receptor agonist and basal insulin is proving convenient, particularly in obese and insulin-resistant patients, who may experience weight gain and hypoglycemia in association with increased doses of insulin. ${ }^{73}$ Once-daily fixed-dose GLP1-receptor agonist/basal insulin CT allows administration of these two agents together in a way that could be more convenient for patients, potentially increasing their adherence. ${ }^{73}$ However, these fixed-dose combinations do not allow adjustment of the dosage of individual components, and further data are needed to assess whether they may provide a real adherence advantage versus separate administration of the GLP1-receptor agonist and basal insulin. Indeed, some patients could benefit more from a flexible combination that allows individual titration of insulin or GLP1-receptor agonist that cannot be achieved using FDCT. ${ }^{74}$

Other advances have also been made in GLP1-receptor agonist-delivery devices. For example, development of a device with a hidden, ready-attached needle (dulaglutide, Table 3) may be helpful for patients with a fear of needles. In addition, development of a subcutaneous implantable device with a duration of action of 6-12 months (exenatide) has been evaluated in clinical trials, and a new drug application has been submitted to the US Food and Drug Administration.

Although the studies reviewed in the previous subsection focused on frequency of administration of GLP1-receptor agonists, some findings also related to dosage formulation and injection device. For example, in the analysis of data from three Phase III trials, adherence was better with once-weekly injectable albiglutide than with oral antihyperglycemic therapy, even if the latter was given as a once-daily pill. ${ }^{65}$ In addition, discrete-choice experiments designed to elicit patient preferences for features of GLP1-receptor agonists indicated that delivery by a multiuse pen $^{64}$ and delivery system in general $^{68}$ were important features. In the latter 
study, ${ }^{68}$ prior to the discrete-choice experiment, similar proportions of participants stated that they would or would not be willing to take a diabetes medication that required an injection for each dose (38\% vs 39\%). However, after completing the discrete-choice experiment and viewing videos demonstrating use of the dulaglutide- and liraglutidedelivery devices, significantly more participants indicated that they were willing to take the medication represented by the dulaglutide profile than the medication represented by the liraglutide profile $(77 \%$ vs $31 \%, P<0.0001)$. These data suggest that reluctance to use injectable therapy may be overcome by use of a patient-friendly delivery device, and are supported by the results of a 4-week trial in which 211 injection-naïve patients with type 2 diabetes evaluated the dulaglutide single-dose pen. ${ }^{75}$ In this study, the final injectionsuccess rate was $99.1 \%$, and $>96 \%$ of patients reported that the device was easy to use, they were satisfied with the device, and they would be willing to continue its use after the study. Overall, $53.3 \%$ of patients reported no pain from the injection, and there was a significant reduction from baseline to week 4 in patients' fear of self-injection (as assessed by a modified self-injecting subscale of the Diabetes Fear of Injecting and Self-Testing Questionnaire). Most patients favored not having to attach, touch, or see the needle $(99 \%$, $98.6 \%$, and $95.7 \%$, respectively).

\section{Patient-reported outcomes}

Patient-reported outcomes, such as those related to treatment satisfaction, are also useful in the context of medication adherence. A positive association between treatment satisfaction and adherence or compliance has been documented in a number of conditions, including diabetes. ${ }^{76}$ Both greater treatment satisfaction as a consequence of better adherence and better adherence as a consequence of greater treatment satisfaction have been reported. ${ }^{76}$ Studies with GLP1-receptor agonists are relevant in this context.

In a randomized open-label study with exenatide, treatment satisfaction (assessed by the Diabetes Treatment Satisfaction Questionnaire - status [DTSQ-s]) and weight-related quality of life (Impact of Weight on Quality of Life - Lite) were significantly improved among patients with type 2 diabetes who were switched from twice-daily to once-weekly exenatide from weeks 30 to $52 .{ }^{77}$ In a series of randomized trials in patients with type 2 diabetes receiving dulaglutide primarily as add-on therapy, once-weekly dulaglutide was associated with improvements in treatment satisfaction (assessed by DTSQ-s and DTSQ - change [DTSQ-c]) and perceived hypoglycemia compared with placebo and exenatide twice daily at 26 and/or 52 weeks. ${ }^{78}$
Additional findings showed significantly better scores in the Ability to Perform Physical Activities of Daily Living instrument $(P<0.001)$, EQ-5D UK index $(P=0.001)$ and the Adult Low Blood Sugar Survey (total score, $P=0.003$; worry subscale, $P=0.003$; behavior subscale, $P=0.038$ ) with dulaglutide $1.5 \mathrm{mg}$ than with insulin glargine. ${ }^{79} \mathrm{~A}$ 26-week randomized open-label trial showed greater treatment satisfaction (assessed by the DTSQ) with once-daily liraglutide injections compared with once-daily oral sitagliptin (both as add on to metformin) in patients with type 2 diabetes. ${ }^{80}$ Once-daily liraglutide was also associated with greater treatment satisfaction (assessed by the DTSQ-c and DTSQ-s) and greater perceived reductions in hypoglycemia and hyperglycemia than twice-daily exenatide in a similar study. ${ }^{81}$ Taken together, these results support the conclusion that less frequent dosage administration of GLP1-receptor agonists is associated with greater treatment satisfaction and improved quality of life, outcomes that may lead to increased adherence. $^{76}$

\section{A framework for the future}

Targets for future research and an organizational framework for consideration of published adherence interventions in the area of nonadherence in type 2 diabetes have been proposed. ${ }^{82}$ It is well recognized that potential barriers to adherence can be categorized as relating to the patient, social and economic issues, provider behavior, the condition/disease, therapy, and the health care system. However, although these factors are generally well-known predictors of nonadherence, their relationship with adherence is surprisingly weak, given the number of research articles in this area. ${ }^{82}$ In an attempt to shed light on the reasons that current strategies for reducing nonadherence are largely ineffective, Blackburn et al proposed that future adherence interventions should be classified on the basis of the source, nature, and target of the intervention. ${ }^{82}$ Other potential aids include telemedicine-assisted and grouptherapy-based interventions. ${ }^{87,88}$

\section{Conclusion}

In conclusion, adherence to antihyperglycemic medication among patients with type 2 diabetes is often suboptimal, and this can have important clinical consequences related to glycemic control, hospitalization, and diabetic complications. Along with a shared decision-making approach, strategies that help to improve adherence to antihyperglycemic drug therapy include better tolerability profiles, less frequent dosing, and advances in formulation and delivery device. GLP1-receptor agonists improve glycemic control, promote weight loss, and generally have a low risk of hypoglycemia, 
but require subcutaneous administration. Evolution of the class of GLP1-receptor agonists, such as the development of dulaglutide, which offers once-weekly administration via a single-dose ready-to-use pen device, provides an example of how advances in drug technology can lead to better adherence and in turn may help to achieve better clinical outcomes.

\section{Acknowledgments}

The authors would like to thank Greg Plosker and Dr Janet Douglas (Rx Communications, Mold, UK) for medical writing assistance with the preparation of this article, funded by Eli Lilly and Company.

\section{Disclosure}

Francesco Giorgino discloses: Advisory Boards: AstraZeneca/ BMS, Eli Lilly, Roche Diagnostics, and Takeda. Consultant: AstraZeneca/BMS, Boehringer Ingelheim, Lifescan, Merck Sharp \& Dohme, Novo Nordisk, and Sanofi Research. Support: AstraZeneca/BMS, Eli Lilly Lifescan, Sanofi, and Takeda. Valeria Pechtner, Raffaella Gentilella and Antonella Corcos are employees and stockholders of Eli Lilly and Company. Alfred Penfornis discloses congress invitations, honoraria and consultancies from Abbott and Medtronic. Alfred Penfornis has received fees for consultancy, advisory boards, speaking, travel or accommodation from Ascencia, LifeScan, Sanofi, Lilly, Novartis, MSD, AstraZeneca, Abbott, Novo Nordisk and Medtronic. The authors report no other conflicts of interest in this work.

\section{References}

1. International Diabetes Federation. IDF Diabetes Atlas. 7 th ed. Brussels: IDF; 2015.

2. Cheung BM, Ong KL, Cherny SS, Sham PC, Tso AW, Lam KS. Diabetes prevalence and therapeutic target achievement in the United States, 1999 to 2006. Am J Med. 2009;122(5):443-453.

3. Guo XH. The value of short-and long-acting glucagon-like peptide-1 agonists in the management of type 2 diabetes mellitus: experience with exenatide. Curr Med Res Opin. 2016;32(1):61-76.

4. World Health Organization. Adherence to Long-Term Therapies: Evidence for Action. Geneva: WHO; 2003.

5. Asche C, LaFleur J, Conner C. A review of diabetes treatment adherence and the association with clinical and economic outcomes. Clin Ther. 2011;33(1):74-109.

6. Hansen RA, Farley JF, Droege M, Maciejewski ML. A retrospective cohort study of economic outcomes and adherence to monotherapy with metformin, pioglitazone, or a sulfonylurea among patients with type 2 diabetes mellitus in the United States from 2003 to 2005. Clin Ther. 2010;32(7):1308-1319.

7. Ayyagari R, Wei W, Cheng D, Pan C, Signorovitch J, Wu EQ. Effect of adherence and insulin delivery system on clinical and economic outcomes among patients with type 2 diabetes initiating insulin treatment. Value Health. 2015;18(2):198-205.

8. Chang PY, Chien LN, Lin YF, Chiou HY, Chiu WT. Nonadherence of oral antihyperglycemic medication will increase risk of end-stage renal disease. Medicine (Baltimore). 2015;94(47):e2051.
9. de Galan BE. Insulin glargine $300 \mathrm{U} / \mathrm{mL}$ in the management of diabetes: clinical utility and patient perspectives. Patient Prefer Adherence. 2016; 10:2097-2106.

10. Tibaldi JM. Evolution of insulin: from human to analog. Am J Med. 2014;127(10):S25-S38.

11. Segal AR, Vootla T, Beaser RS. Insulin: making sense of current options. Endocrinol Metab Clin North Am. 2016;45(4):845-874.

12. Clifford S, Perez-Nieves M, Skalicky AM, Reaney M, Coyne KS. A systematic literature review of methodologies used to assess medication adherence in patients with diabetes. Curr Med Res Opin. 2014; 30(6):1071-1085

13. Cramer JA, Roy A, Burrell A, et al. Medication compliance and persistence: terminology and definitions. Value Health. 2008;11(1): 44-47.

14. García-Pérez LE, Alvarez M, Dilla T, Gil-Guillén V, Orozco-Beltrán D. Adherence to therapies in patients with type 2 diabetes. Diabetes Ther. 2013;4(2):175-194.

15. Osterberg L, Blaschke T. Adherence to medication. $N$ Engl J Med. 2005;353(5):487-497.

16. Krass I, Schieback P, Dhippayom T. Adherence to diabetes medication: a systematic review. Diabet Med. 2015;32(6):725-737.

17. Odegard PS, Capoccia K. Medication taking and diabetes a systematic review of the literature. Diabetes Educ. 2007;33(6):1014-1029.

18. Sapkota S, Brien JA, Greenfield J, Aslani P. A systematic review of interventions addressing adherence to anti-diabetic medications in patients with type 2 diabetes: impact on adherence. PLoS One. 2015;10(2): e0118296.

19. Egede LE, Gebregziabher M, Echols C, Lynch CP. Longitudinal effects of medication nonadherence on glycemic control. Ann Pharmacother. 2014;48(5):562-570.

20. Iglay K, Cartier SE, Rosen VM, et al. Meta-analysis of studies examining medication adherence, persistence, and discontinuation of oral antihyperglycemic agents in type 2 diabetes. Curr Med Res Opin. 2015;31(7): 1283-1296.

21. Peyrot M, Barnett AH, Meneghini LF, Schumm-Draeger PM. Factors associated with injection omission/non-adherence in the Global Attitudes of Patients and Physicians in Insulin Therapy study. Diabetes Obes Metab. 2012;14(12):1081-1087.

22. Carls G, Tuttle E, Tan RD, et al. Differences in T2DM therapy outcomes in trials vs. the real-world (RW): identifying the impact of poor adherence. Late Breaking Abstracts. Poster presented at: 76th Scientific Sessions of the American Diabetes Association; June 10-14, 2016; New Orleans, LA.

23. Brown MT, Bussell JK. Medication adherence: WHO cares? Mayo Clin Proc. 2011;86(4):304-314.

24. Marzec LN, Maddox TM. Medication adherence in patients with diabetes and dyslipidemia: associated factors and strategies for improvement. Curr Cardiol Rep. 2013;15(11):418.

25. Odegard PS, Gray SL. Barriers to medication adherence in poorly controlled diabetes mellitus. Diabetes Educ. 2008;34(4):692-697.

26. Nau DP. Recommendations for improving adherence to type 2 diabetes mellitus therapy: focus on optimizing oral and non-insulin therapies. Am J Manag Care. 2012;18(3 Suppl):S49-S54.

27. Tiv M, Viel JF, Mauny F, et al. Medication adherence in type 2 diabetes: the ENTRED study 2007, a French population-based study. PLoS One. 2012;7(3):e32412.

28. Reach G, Pechtner V, Gentilella R, Corcos A, Ceriello A. Clinical inertia and its impact on treatment intensification in people with type 2 diabetes mellitus. Diabetes Metab. 2017;43(6):501-511.

29. Owens DR, Monnier L, Barnett AH. Future challenges and therapeutic opportunities in type 2 diabetes: changing the paradigm of current therapy. Diabetes Obes Metab. 2017;19(10):1339-1352.

30. Adams AS, Trinacty CM, Zhang F, et al. Medication adherence and racial differences in A1C control. Diabetes Care. 2008;31(5):916-921.

31. Pladevall M, Williams LK, Potts LA, Divine G, Xi H, Lafata JE. Clinical outcomes and adherence to medications measured by claims data in patients with diabetes. Diabetes Care. 2004;27(12): 2800-2805. 
32. Cobden D, Lee WC, Balu S, Joshi AV, Pashos CL. Health outcomes and economic impact of therapy conversion to a biphasic insulin analog pen among privately insured patients with type 2 diabetes mellitus. Pharmacotherapy. 2007;27(7):948-962.

33. Ho PM, Rumsfeld JS, Masoudi FA, et al. Effect of medication nonadherence on hospitalization and mortality among patients with diabetes mellitus. Arch Intern Med. 2006;166(17):1836-1841.

34. Boye KS, Garcia-Perez LE, Curtis S, Lage MJ. Association between adherence to glucose-lowering agents and outcomes among patients age $=65$ with type 2 diabetes. Poster presented at: 76th Scientific Sessions of the American Diabetes Association; June 10-14, 2016; New Orleans, LA.

35. Curtis S, Boye KS, Lage MJ, et al. Increased adherence to glucose-lowering agents is associated with improvements in acute care outcomes. Poster presented at: 76th Scientific Session of the American Diabetes Association; June 10-14, 2016; New Orleans, LA.

36. Juarez DT, Tan C, Davis J, Mau M. Factors affecting sustained medication adherence and its impact on healthcare utilization in patients with diabetes. J Pharm Health Serv Res. 2013;4(2):89-94.

37. Nguyen H, Cappell K, Nelson J, Chu BC, Johnston S. Retrospective study of the association between adherence to glucagon-like peptide-1 receptor agonist therapy and hospitalization risk and costs. Poster presented at: 76th Scientific Sessions of the American Diabetes Association; June 10-14, 2016; New Orleans, LA.

38. Buysman EK, Liu F, Hammer M, Langer J. Impact of medication adherence and persistence on clinical and economic outcomes in patients with type 2 diabetes treated with liraglutide: a retrospective cohort study. Adv Ther. 2015;32(4):341-355.

39. Claxton AJ, Cramer J, Pierce C. A systematic review of the associations between dose regimens and medication compliance. Clin Ther. 2001; 23(8):1296-1310.

40. Kruk ME, Schwalbe N. The relation between intermittent dosing and adherence: preliminary insights. Clin Ther. 2006;28(12): 1989-1995.

41. Recker RR, Gallagher R, MacCosbe PE. Effect of dosing frequency on bisphosphonate medication adherence in a large longitudinal cohort of women. Mayo Clin Proc. 2005;80(7):856-861.

42. Polonsky WH, Fisher L, Hessler D, Bruhn D, Best JH. Patient perspectives on once-weekly medications for diabetes. Diabetes Obes Metab. 2011;13(2):144-149.

43. Cuddihy RM, Borgman SK. Considerations for diabetes: treatment with insulin pen devices. Am J Ther. 2013;20(6):694-702.

44. Davies MJ, Gagliardino JJ, Gray LJ, Khunti K, Mohan V, Hughes R. Real-world factors affecting adherence to insulin therapy in patients with type 1 or type 2 diabetes mellitus: a systematic review. Diabet Med. 2013;30(5):512-524.

45. Doggrell SA, Chan V. Adherence to insulin treatment in diabetes: can it be improved? J Diabetes. 2015;7(3):315-321.

46. Gaddi AV, Benedetto D, Capello F, et al. Oral antidiabetic therapy in a large Italian sample: drug supply and compliance for different therapeutic regimens. Public Health. 2014;128(1):70-76.

47. Han S, Iglay K, Davies MJ, Zhang Q, Radican L. Glycemic effectiveness and medication adherence with fixed-dose combination or coadministered dual therapy of antihyperglycemic regimens: a meta-analysis. Curr Med Res Opin. 2012;28(6):969-977.

48. Kirkman MS, Rowan-Martin MT, Levin R, et al. Determinants of adherence to diabetes medications: findings from a large pharmacy claims database. Diabetes Care. 2015;38(4):604-609.

49. Chapman RH, Petrilla AA, Benner JS, Schwartz JS, Tang SS. Predictors of adherence to concomitant antihypertensive and lipid-lowering medications in older adults: a retrospective, cohort study. Drugs Aging. 2008;25(10):885-892.

50. Benner JS, Chapman RH, Petrilla AA, Tang SS, Rosenberg N, Schwartz JS. Association between prescription burden and medication adherence in patients initiating antihypertensive and lipid-lowering therapy. Am J Health Syst Pharm. 2009;66(16):1471-1477.
51. Nachega JB, Parienti JJ, Uthman OA, et al. Lower pill burden and once-daily antiretroviral treatment regimens for HIV infection: a metaanalysis of randomized controlled trials. Clin Infect Dis. 2014;58(9): $1297-1307$.

52. Blüher M, Kurz I, Dannenmaier S, Dworak M. Pill burden in patients with type 2 diabetes in Germany: subanalysis from the prospective, noninterventional PROVIL study. Clin Diabetes. 2015;33(2):55-61.

53. van Galen KA, Nellen JF, Nieuwkerk PT. The effect on treatment adherence of administering drugs as fixed-dose combinations versus as separate pills: systematic review and meta-analysis. AIDS Res Treat. 2014;2014:967073.

54. Inzucchi SE, Bergenstal RM, Buse JB, et al. Management of hyperglycemia in type 2 diabetes: a patient-centered approach. Diabetes Care. 2012;35(6):1364-1379.

55. Inzucchi SE, Bergenstal RM, Buse JB, et al. Management of hyperglycemia in type 2 diabetes, 2015 - a patient-centered approach: update to a position statement of the American Diabetes Association and the European Association for the Study of Diabetes. Diabetes Care. 2015; 38(1):140-149.

56. Hoffmann TC, Légaré F, Simmons MB, et al. Shared decision making: what do clinicians need to know and why should they bother? Med $J$ Aust. 2014;201(1):35-39.

57. Branda ME, LeBlanc A, Shah ND, et al. Shared decision making for patients with type 2 diabetes: a randomized trial in primary care. $B M C$ Health Serv Res. 2013;13:301.

58. Wilson SR, Strub P, Buist AS, et al. Shared treatment decision making improves adherence and outcomes in poorly controlled asthma. Am J Respir Crit Care Med. 2010;181(6):566-577.

59. Sapkota S, Brien JA, Greenfield J, Aslani P. A systematic review of interventions addressing adherence to anti-diabetic medications in patients with type 2 diabetes: components and interventions. PLoS One. 2015;10(6): 0128581

60. Dalsgaard NB, Brønden A, Vilsbøll T, Knop FK. Cardiovascular safety and benefits of GLP-1 receptor agonists. Expert Opin Drug Saf. 2017;16(3):351-363.

61. Malmenäs M, Bouchard JR, Langer J. Retrospective real-world adherence in patients with type 2 diabetes initiating once-daily liraglutide $1.8 \mathrm{mg}$ or twice-daily exenatide $10 \mu \mathrm{g}$. Clin Ther. 2013;35(6): 795-807.

62. Cai J, Wang Y, Baser O, Xie L, Chow W. Comparative persistence and adherence with newer anti-hyperglycemic agents to treat patients with type 2 diabetes in the United States. J Med Econ. 2016;19(12): $1175-1186$.

63. Johnston SS, Nguyen H, Felber E, et al. Retrospective study of adherence to glucagon-like peptide-1 receptor agonist therapy in patients with type 2 diabetes mellitus in the United States. Adv Ther. 2014;31(11): 1119-1133.

64. Qin L, Chen S, Flood E, et al. Glucagon-like peptide-1 receptor agonist treatment attributes important to injection-naïve patients with type 2 diabetes mellitus: a multinational preference study. Diabetes Ther. 2017; 8(2):321-334

65. Leiter LA, Scott RA, Ye J, Carr MC. Medication compliance rates of weekly albiglutide vs. daily oral comparators in phase III trials. Diabetes. 2014;63 Suppl 1:A255.

66. Alatorre C, Landó LF, Yu M, et al. Treatment patterns in patients with type 2 diabetes mellitus treated with GLP-1 receptor agonists: higher adherence and persistence with dulaglutide compared to exenatide QW and liraglutide. Diabetes Obes Metab. 2017;19(7):953-961.

67. Hauber AB, Nguyen H, Posner J, Ervin C, LaRue S, Kalsekar I. Patient preferences for frequency of glucagon-like peptide-1 receptor agonist (GLP-1RA) injections in the treatment of type 2 diabetes. Value Health. 2014;17(3):A255.

68. Gelhorn HL, Poon JL, Davies EW, Paczkowski R, Curtis SE, Boye KS. Evaluating preferences for profiles of GLP-1 receptor agonists among injection-naïve type 2 diabetes patients in the UK. Patient Prefer Adherence. 2015;9:1611-1622. 
69. Gelhorn HL, Stringer SM, Brooks A, et al. Preferences for medication attributes among patients with type 2 diabetes mellitus in the UK. Diabetes Obes Metab. 2013;15(9):802-809.

70. European Medicines Agency. Albiglutide (Eperzan) [summary of product characteristics]. Available from: http://www.ema.europa. eu/docs/en_GB/document_library/EPAR_-_Product_Information/ human/002735/WC500165117.pdf. Accessed June 27, 2016.

71. European Medicines Agency. Exenatide (Bydureon) [summary of product characteristics]. Available from: http://www.ema.europa. eu/docs/en_GB/document_library/EPAR_-_Product_Information/ human/002020/WC500108241.pdf. Accessed June 27, 2016.

72. European Medicines Agency. Dulaglutide (Trulicity) [summary of product characteristics]. Available from: http://ec.europa.eu/health/ documents/community-register/2014/20141121130063/anx_130063_ en.pdf. Accessed June 27, 2016.

73. Gallwitz B. The future of combination therapies of insulin with a glucagon-like peptide-1 receptor agonist in type 2 diabetes: is it advantageous? Eur Endocrinol. 2014;10(2):98-99.

74. Vedtofte L, Knop FK, Vilsbøll T. Efficacy and safety of fixed-ratio combination of insulin degludec and liraglutide (IDegLira) for the treatment of type 2 diabetes. Expert Opin Drug Saf. 2017;16(3):387-396.

75. Matfin G, van Brunt K, Zimmermann AG, Threlkeld R, Ignaut DA. Safe and effective use of the once weekly dulaglutide single-dose pen in injection-naive patients with type 2 diabetes. J Diabetes Sci Tech. 2015; 9(5):1071-1079.

76. Barbosa CD, Balp MM, Kulich K, Germain N, Rofail D. A literature review to explore the link between treatment satisfaction and adherence, compliance, and persistence. Patient Prefer Adherence. 2012;6:39-48.

77. Best JH, Boye KS, Rubin RR, Cao D, Kim TH, Peyrot M. Improved treatment satisfaction and weight-related quality of life with exenatide once weekly or twice daily. Diabet Med. 2009;26(7):722-728.

78. Reaney M, Yu M, Lakshmanan M, Pechtner V, van Brunt K. Treatment satisfaction in people with type 2 diabetes mellitus treated with onceweekly dulaglutide: data from the AWARD-1 and AWARD-3 clinical trials. Diabetes Obes Metab. 2015;17(9):896-903.

79. Yu M, van Brunt K, Varnado OJ, Boye KS. Patient-reported outcome results in patients with type 2 diabetes treated with once-weekly dulaglutide: data from the AWARD phase III clinical trial programme. Diabetes Obes Metab. 2016;18(4):419-424.
80. Davies M, Pratley R, Hammer M, Thomsen AB, Cuddihy R. Liraglutide improves treatment satisfaction in people with type 2 diabetes compared with sitagliptin, each as an add on to metformin. Diabet Med. 2011;28(3):333-337.

81. Schmidt WE, Christiansen JS, Hammer M, Zychma MJ, Buse JB. Patient-reported outcomes are superior in patients with type 2 diabetes treated with liraglutide as compared with exenatide, when added to metformin, sulphonylurea or both: results from a randomized, openlabel study. Diabet Med. 2011;28(6):715-723.

82. Blackburn DF, Swidrovich J, Lemstra M. Non-adherence in type 2 diabetes: practical considerations for interpreting the literature. Patient Prefer Adherence. 2013;7:183-189.

83. Roberts AW, Crisp GD, Esserman DA, Roth MT, Weinberger M, Farley JF. Patterns of medication adherence and health care utilisation among patients with chronic disease who were enrolled in a pharmacy assistance program. N C Med J. 2014;75(3):310-318.

84. European Medicines Agency. Exenatide (Byetta) [summary of product characteristics]. Available from: http://www.ema.europa.eu/docs/en GB/document_library/EPAR_-_Product_Information/human/000698/ WC500051845.pdf. Accessed June 27, 2016.

85. European Medicines Agency. Liraglutide (Victoza) [summary of product characteristics]. Available from: http:/www.ema.europa. eu/docs/en_GB/document_library/EPAR_-_Product_Information/ human/001026/WC500050017.pdf. Accessed June 27, 2016.

86. European Medicines Agency. Lixisenatide (Lyxumia) [summary of product characteristics]. Available from: http://www.ema.europa. eu/docs/en_GB/document_library/EPAR_-_Product_Information/ human/002445/WC500140401.pdf. Accessed June 27, 2016.

87. Cassimatis M, Kavanagh DJ. Effects of type 2 diabetes behavioural telehealth interventions on glycaemic control and adherence: a systematic review. J Telemed Telecare. 2012;18(8):447-450.

88. Aliha JM, Asgari M, Khayeri F, Ramazani M, Farajzadegan Z, Javaheri J. Group education and nurse-telephone follow-up effects on blood glucose control and adherence to treatment in type 2 diabetes patients. Int J Prev Med. 2013;4(7):797-802.
Patient Preference and Adherence

\section{Publish your work in this journal}

Patient Preference and Adherence is an international, peer-reviewed, open access journal that focuses on the growing importance of patient preference and adherence throughout the therapeutic continuum. Patient satisfaction, acceptability, quality of life, compliance, persistence and their role in developing new therapeutic modalities and compounds to optimize

\section{Dovepress}

clinical outcomes for existing disease states are major areas of interest for the journal. This journal has been accepted for indexing on PubMed Central. The manuscript management system is completely online and includes a very quick and fair peer-review system, which is all easy to use. Visit http://www. dovepress.com/testimonials.php to read real quotes from published authors. 